\title{
Strijdtonelen \\ De Tweede Wereldoorlog in de populaire historische cultuur
}

\author{
Rede \\ In verkorte vorm uitgesproken \\ bij de aanvaarding van het ambt van \\ bijzonder hoogleraar Populaire Historische Cultuur en Oorlog \\ aan de Erasmus School of History, Culture and Communication \\ van de Erasmus Universiteit Rotterdam \\ op vrijdag 25 oktober 2013 \\ door
}

Kees Ribbens 

Mijnheer de Rector Magnificus,

Dames en heren,

De Tweede Wereldoorlog kent vele gedaanten. ${ }^{1}$ Er bestaat een oorlog die we in Nederland gezamenlijk herdenken op 4 en 5 mei. Er bestaat een oorlog die versteend is in monumenten. Er bestaat een oorlog waarvan we kennis kunnen nemen via boeken, artikelen en debatten in de geschiedwetenschap. Er bestaat een oorlog die gestalte krijgt in het onderwijs en een oorlog in exposities en musea. Het zijn de verschijningsvormen van de oorlog van geëngageerde betrokkenen en herdenkingscomité's, van historici en publicisten, van educatieve deskundigen en tentoonstellingsmakers.

Deze verschillende representaties en herinneringspraktijken komen met elkaar in aanraking, zijn zich doorgaans bewust van elkaar en ook, tot op zekere hoogte, van het onderscheid in wat zij doen en beogen. Alle vormen dragen er toe bij dat de herinnering aan de oorlog levend blijft en streven ernaar die herinnering te delen en over te dragen. Zij geven de oorlog voor en vanuit de Nederlandse samenleving weer. Daarbij doen ze een beroep op historische feiten en ijkpunten zoals 10 mei 1940 en Dolle Dinsdag, koningin Wilhelmina en Anton Mussert, Kamp Westerbork en de razzia van Rotterdam.

Maar er is ook een ander gezicht van de Tweede Wereldoorlog. En het is dit gezicht dat hier vanmiddag centraal staat. Als een oorlog die dag in dag uit alom aanwezig is, die door velen - zo niet door allen - wordt waargenomen, maar die los lijkt te staan van de zojuist genoemde verschijningsvormen. Het is een oorlog die gestalte krijgt in bioscopen en in de huiskamer, in het musicaltheater van Soldaat van Oranje, op toeristische bestemmingen in binnen- en buitenland, als individuele bezigheid en in verenigingsverband. Het is de oorlog van avonturenromans en stripverhalen, van computergames en websites, van films en re-enactment, kortom de oorlogsverbeeldingen van en voor doorsnee burgers, dagjesmensen en hobbyisten.

Deze en soortgelijke oorlogsverbeeldingen - die een ruime variatie aan strijdtonelen vormen - zijn al sinds het uitbreken van de oorlog in groten getale aanwezig, krijgen steeds opnieuw gestalte en weten uiteenlopende publieksgroepen aan te spreken. Dit hybride geheel aan verschijningsvormen van de Tweede Wereldoorlog en de manieren waarop ze tot stand komen en benut 
worden vormt de populaire historische cultuur van de oorlog. In dit fenomeen staan, anders dan in de eerdergenoemde geïnstitutionaliseerde categorieën, kennisoverdracht en bezinning op leed en verantwoordelijkheid niet steeds centraal. Sterker nog, feiten worden niet per definitie boven fictie gesteld door een sterk visueel ingesteld publiek dat niet steeds doelbewust op zoek is naar informatie over de oorlog. Deze populaire historische cultuur trekt zich, blijkens vertolkingen die een internationaal publiek vinden, betrekkelijk weinig aan van het nationale kader waarmee veel van de meer geïnstitutionaliseerde varianten van de oorlogsverbeeldingen sterk vertrouwd en verweven zijn. Zo bereiken deze vertolkingen een publiek dat, met wisselend succes, ook doelgroep vormt van herdenkers, historici en educatoren.

De herinneringsprofessionals - en tot hun wereld behoor ik zelf - hebben tot hun ongenoegen doorgaans weinig grip op dergelijke verbeeldingsvarianten en zij nemen deze vaak ook onvoldoende serieus. De veronderstelling is dat de populaire verbeeldingen - evenals degenen die ze maken, verspreiden en tot zich nemen - niet uitblinken door ontzag voor de historische realiteit. Producenten en consumenten zouden niet gedreven worden door de wens inzicht te verwerven in de complexe en genuanceerde historische ontwikkelingen. Mede vanwege commerciële doeleinden zou het fenomeen nagenoeg betekenisloos zijn. Uit die veronderstellingen spreekt een strijdtoneel van culturele hiërarchieën dat aandacht verdient. Want enerzijds is het de vraag in hoeverre dergelijke verwachtingen correct zijn en of ze steeds in gelijke mate opgaan voor alle uiteenlopende populaire vertolkingsvormen van de oorlog. Anderzijds: zelfs indien populaire historische oorlogsverbeeldingen in belangrijke mate uit clichévoorstellingen bestaan, dan weerhoudt dat ontvangers er niet van om er betekenis aan te verlenen. Het bestaan van de veelsoortige vertolkingen en het aanzienlijke bereik daarvan dwingen ons tot reflectie op hun aard en functioneren om zicht te krijgen op hun betekenis en op de wijze waarop zij zich verhouden tot de rol van herinneringsprofessionals.

Om deze kwestie in perspectief te plaatsen zal ik vandaag eerst een korte schets bieden van de hedendaagse populaire historische cultuur, ${ }^{2}$ die tevens de spanning illustreert tussen de verschillende kaders waarin het verleden wordt gepresenteerd en eigen gemaakt. Vervolgens zal de historische consument worden omschreven. Na een uiteenzetting van de redenen van onze oorlogsfascinatie volgt een beschrijving van de ontwikkelingen in enkele geïnstitutionaliseerde delen van de historische cultuur en een kenschets van onderzoek naar populaire oorlogsvertolkingen tot dusverre. Dat brengt ons bij het belang van het spelelement en het daarmee samenhangende idee van actieve participatie in de historische cultuur. Tot slot passeren twee andere karakteristieken van de hedendaagse oorlogsverbeeldingen de revue, te weten het transnatio- 
nale element en poreuze genreverhoudingen, alvorens ik afsluit met een conclusie en dankwoord.

De populaire historische cultuur zoals die zich in de afgelopen decennia in een groot deel van de westerse wereld, en ook daarbuiten, heeft ontwikkeld kent een veelvoud aan uitingsvormen van historische belangstelling en bijbehorend aanbod. De publieke omgang met het verleden - en met wat vrijelijk geassocieerd wordt met het verleden - blijft opvallend sterk aanwezig in westerse, post-industriële maatschappijen die in hun moderne zelfbewustzijn zozeer op vernieuwing gericht zijn. Geschiedenis is na de ingrijpende, veelal als breuk ervaren gebeurtenissen van de Tweede Wereldoorlog en na golven van democratisering, ontzuiling en individualisering een tijdlang opgevat als irrelevante ballast aan tradities, als achterhaald, stijf en stoffig. Geschiedenis leek een ouderwets verhaal dat losstond van de hedendaagse samenleving. Maar sinds de late twintigste eeuw maakt historische belangstelling een opvallende comeback.

In Britse media werd history al aangeduid als 'the new rock and roll'. ${ }^{3}$ Maar ditmaal omvat het geen min of meer eenduidig verhaal in opgaande lijn waarin de wederwaardigheden van de politieke en maatschappelijke elite gelijk werden gesteld aan de nationale geschiedenis. Geschiedenis is nu veeleer een bonte verzameling verhalen waarin in beginsel ruimte lijkt te zijn weggelegd voor ieder historisch personage. Geen medium of informatiedrager blijft onbenut om een verhaal te vertellen, waarin het woord niet per definitie dominant is, maar waarin juist het visuele element sterk meespreekt. Daarin wordt het verleden bij voorkeur voorgesteld als iets dat nog tastbaar is, als het ware beschikbaar om fysiek en emotioneel opnieuw 'beleefd' te worden.

Het begrip erfgoed geldt in binnen- en buitenland als een populair label voor deze wedergeboorte van geschiedenis. In de historische hausse die hierachter schuilging, kwamen velen in aanraking met sporen van het verleden die op hedendaagse wijzen geïnterpreteerd werden. Voor tal van instellingen binnen het nu als erfgoedsector bekend staande domein vormde de nieuwe interesse een uitgelezen kans om kennis en collecties te delen met een breder publiek. Historische musea, die vooral vanaf de jaren zeventig een toegenomen diversiteit kenden aan gepresenteerde en verzamelde onderwerpen, probeerden waar mogelijk in te springen op het publieke enthousiasme. Lokale en regionale musea en archieven lieten zich niet onbetuigd, al bleven de activiteiten ook hier vaker aanbod- dan vraaggestuurd.

De hedendaagse ingang tot het verleden wordt gekarakteriseerd door een groot areaal aan historische presentaties over zeer uiteenlopende onderwerpen. Door de grote keuzemogelijkheid appelleert het aan uiteenlopende voorkeuren van groepen en individuen om in aanraking te komen met geschiedenis. 
Dit fenomeen wordt op twee manieren beoordeeld. Professionals vrezen dat de fragmentering van het geschiedbeeld het zicht op de samenhang van dat verleden verzwakt. ${ }^{4}$ Maar het kan mijns inziens evenzeer gezien worden als een gevarieerd aanbod dat de mogelijkheid in zich draagt meer recht te doen aan de diversiteit van het verleden.

In de politieke en bestuurlijke arena werd deze populariteit van het verleden eveneens opgemerkt, maar hier was de klassieke tendens om geschiedenis te instrumentaliseren. Dit kwam vooral voort uit zorg over het ontbreken van serieus geachte historische belangstelling, opgevat als de viering van de collectieve Nederlandse identiteit. De vrees was dat die identiteit in tijden van een toegenomen multicultureel karakter van de samenleving en van de culturele impact van globalisering onder druk stond. ${ }^{5}$ Deze zorg wilde men wegnemen door het verleden - nadrukkelijk opgevat als het nationale verleden - met vernieuwd elan te presenteren op relatief vertrouwde wijze. Het gevolg was dat met parlementaire instemming het initiatief werd genomen voor een nationale historische canon en een nationaal historisch museum. En in beide was ruimte voorzien voor de oorlog.

De canon kwam tot stand, opgebouwd uit vijftig vensters waarvan er één was gewijd aan de Tweede Wereldoorlog en één aan de Jodenvervolging. ${ }^{6}$ Uiteindelijk kreeg deze canon in het onderwijscurriculum een bescheiden positie, ook al werd het aanbod op de officiële website aangevuld met filmpjes, suggesties voor jeugdromans, stripverhalen en, onder het kopje 'Er op uit', met musea. Opmerkelijk was vooral dat de lancering van de nationale canon door een groot aantal burgers en instanties werd aangegrepen om hun eigen lokale, regionale, religieuze, politieke of anderszins thematisch ingevulde canon op te stellen. Ook een specifieke oorlogscanon ontbrak niet. ${ }^{7}$ Hoewel het relativeren van de nationale canon zelden een expliciete doelstelling was van de makers van de subcanons, maakte hun activiteit niettemin duidelijk hoezeer de dominantie van het nationale verhaal ondergraven was en werd. ${ }^{8}$ De verwezenlijking van het nationaal historisch museum werd voortijdig beëindigd. Naast bestuurlijke ontevredenheid over de organisatorische gang van zaken rond de vestigingslocatie, speelde politieke onvrede over de beoogde invulling van het museum - die werd aangeduid als postmoderne hutspot ${ }^{9}$ - daarbij een onmiskenbare rol. Het museum liet zich geen rol als identiteitsfabriek voorschrijven, zocht doelbewust vernieuwing door een thematische aanpak (zoals 'Oorlog en Vrede') in plaats van veel nadruk te leggen op chronologie. Het wilde geïnteresseerden nadrukkelijk ruimte bieden voor een eigen invulling.

Pogingen om een eenduidig historisch verhaal over te dragen, een verhaal dat zelfs min of meer ongecompliceerd een collectieve identiteit zou belichamen en nationale trots zou kunnen versterken, blijken onvoldoende aan te slui- 
ten bij de wensen en verwachtingen van belangrijke delen van het publiek. Maar ook bij de betrokken historische professionals, zij het niet om dezelfde redenen. Publieksgroepen lijken te houden van hun eigen verhalen; professionals hebben een zekere neiging het veelvoud aan verhalen te wantrouwen. Al met al levert dit in de vroege 21ste eeuw een weerbarstige historische cultuur op, waarmee niet ongestraft valt te spotten.

We mogen daaruit de les trekken dat de historische 'consument' serieus genomen dient te worden. Deze laat zich niet zomaar door anderen verordonneren wat uit het verleden de moeite waard is om aandacht aan te schenken en op welke wijze dat dient te gebeuren. De term historische consument is hierbij misleidend. Want hij of zij mag op tal van momenten afnemer zijn van wat door anderen wordt aangeboden aan historische informatie en verwante verhalen, maar daarmee is zijn persoonlijke rol en invulling niet afwezig. Het idee dat de hedendaagse historische geïnteresseerde een passieve ontvanger zou zijn, gaat niet op. Beter is het te spreken van een participant in de historische cultuur, als iemand wiens belangstelling voor het verleden, met wisselende intensiteit, mag worden opgevat als het zich toe-eigenen van en daarmee het betekenis verlenen aan geschiedenis. ${ }^{10}$ De rol van deze participanten in de historische cultuur is niet per definitie passief en evenmin statisch; zij zijn geen bijkomstigheid in het aanbod aan historische informatie. De rollen van producent of aanbieder, van verspreider, en van afnemer zijn beweeglijker dan voorheen en dienen juist, vanuit de dynamiek van de historische cultuur, meer begrepen te worden als veranderlijke posities. Vanuit een dergelijke benadering kunnen we een getrouwer beeld krijgen van de afwegingen en activiteiten van de historische participant.

Willen we de prominente aanwezigheid van de Tweede Wereldoorlog in uiteenlopende deelterreinen van de historische cultuur begrijpen, dan rijst de vraag waar de aanhoudende fascinatie voor de oorlog uit voortkomt. Die kan wat betreft de populaire cultuur op drie manieren worden beantwoord. De eerste van deze antwoorden, die in elkaar grijpen, is betrekkelijk eenvoudig. Het feit dat verwijzingen naar de Tweede Wereldoorlog welhaast omnipresent ogen en stuk voor stuk het uitzonderlijke karakter van deze jaren benadrukken - waardoor de oorlog zowel vreemd als vertrouwd overkomt - heeft een intrigerende werking die niet alleen de interesse voor de oorlog versterkt maar tevens de hedendaagse betekenis van deze geschiedenis voortdurend lijkt te bevestigen. Deze spiraalbeweging bouwt voort op twee andere fenomenen.

Enerzijds betreft het een algemene fascinatie voor het fenomeen oorlog. Oorlogsvoorstellingen appelleren aan scherpe tegenstellingen. Veel meer dan in het dagelijks leven - dat zozeer contrasteert met een oorlogssituatie - worden zaken op scherp gezet. Er is sprake van wezenlijke kwesties waarbij het, 
zeker in de verbeelding die ons er op veilige wijze mee in aanraking brengt, niet zelden gaat om leven en dood, om goed en kwaad en om verantwoordelijkheid en schuld. De aantrekkingskracht van oorlog kan schuilen in gevoelige morele vraagstukken over keuzemogelijkheden, maar deze thematiek vormt niet altijd de voornaamste kracht. Het gaat ook om gevoelens en eigenschappen in een zeer gespannen situatie, uitvergroot tot in de overtreffende trap, die we menen te herkennen maar niet in die mate hopen of vrezen te bezitten: angst, heldhaftigheid, solidariteit of roekeloosheid. En daarnaast is er nog een fascinatie voor wat verwerpelijk wordt geacht, zoals geweld en onderdrukking en degenen die zich hieraan te buiten gaan.

Anderzijds berust de interesse voor de oorlog juist in het daadwerkelijk historische karakter van de Tweede Wereldoorlog, temeer nu conflicten met grootschalig geweld een relatief schaars fenomeen zijn geworden in een groot deel van de westerse wereld. Daar komt bij dat de Tweede Wereldoorlog bij uitstek een totale oorlog was die een breed panorama aan levensterreinen bestreek, en daarmee veel ijkpunten voor herkenning biedt. ${ }^{11}$ Het gegeven dat de oorlog niet ver weg is in de tijd speelt een belangrijke, zij het geleidelijk aan kracht afnemende rol. De oorlog vond minder dan een eeuw geleden plaats. Zodoende zijn er nog mensen die het zelf hebben meegemaakt, niet onbelangrijk in een historische cultuur waarin veel waarde wordt gehecht aan ooggetuigen. Het persoonlijke verhaal van de ooggetuige en diens beleving spreken juist in tijden van toegenomen individualisering - aan, omdat het geschiedenis als het ware terugbrengt tot het verhaal van een individu en tegelijkertijd een rechtstreekse en onbemiddelde toegang tot de geschiedenis lijkt te bieden. Mede door de nabijheid in tijd zijn ook materiële sporen nog in relatief ruime mate voorhanden, en steeds meer als zodanig herkenbaar gemaakt, op de oorspronkelijke historische locatie of elders in het herinneringslandschap - zoals in oorlogsmusea. Zeker waar deze sporen zich in de geografische nabijheid bevinden (een begrip dat door eigentijdse mobiliteit en toerisme aanzienlijk is opgerekt) wordt het idee van zintuiglijk tastbare aanwezigheid - een andere karakteristiek van de eigentijdse historische cultuur - belichaamd of versterkt. Deze menselijke en materiële verschijningsvormen van temporele en geografische nabijheid sluiten bovendien goed aan bij de grote waardering voor authenticiteit. Dit tamelijk rekbare begrip, dat het midden houdt tussen de toegekende waarachtigheid van de ooggetuigen en relicten en de onbevangen wijze waarop zij de geschiedenis zouden vertolken, geldt nu eveneens als kernwaarde in de historische cultuur.

Over de wijze waarop de interesse in de Tweede Wereldoorlog zich vertolkt heeft in de populaire cultuur weten we nog onvoldoende. ${ }^{12}$ Daarentegen bestaat er in de academische geschiedbeoefening wel een gedegen overzicht van 
de publicaties die hieruit voortkomen. Al sinds de ontwikkeling van geschiedenis als academische discipline vormt de historiografie een waardevolle vorm van zelfreflectie die laat zien hoe opeenvolgende generaties historici zich verhouden tot voorgangers en collega's en hoe ze beïnvloed blijken door de tijdsgeest. Maar minder duidelijk is welk publiek zij met uiteenlopende publicaties, ook over de Tweede Wereldoorlog, bereiken en wat daarvan de maatschappelijke impact is.

De memory boom in recente decennia leert ons meer over de betekenis die het verleden buiten de academie heeft voor specifieke gemeenschappen en daarmee over de frictie en zelfs concurrentie tussen taaie en diepgewortelde geschiedbeelden. Een groeiend aantal studies toont hoe mensen die bepaalde, veelal ingrijpende gebeurtenissen hebben ondervonden hun herinneringen aan deze geschiedenis verwerken en vormgeven, hoe ze dit verleden inkaderen en van eigentijdse betekenissen voorzien. Het illustreert bovendien hoe zij aandacht vragen of bevechten in eigen kring én daarbuiten, en hoe ze erkenning nastreven voor hun ervaringen in een herinneringslandschap waar ze niet zelden stuiten op gevestigde belangen van dominante geschiedvoorstellingen die zich snel noch eenvoudig laten aanpassen of verdringen. ${ }^{13}$

Ervaringen uit de Tweede Wereldoorlog, met name van joodse en andere vervolgingsslachtoffers, zijn sterk vertegenwoordigd in deze memory studies. ${ }^{14}$ Tal van studies verduidelijken de politieke en maatschappelijke wenselijkheid van een als heroïsch en eensgezind opgevat verleden, waarvan de samenbindende betekenis ook voor de huidige samenleving van groot belang wordt geacht. In schril contrast daarmee staat de strijd die, aanvankelijk soms op een zeer bescheiden zijtoneel, gevoerd wordt door groepen en individuen - kampgevangenen, burgers en militairen uit de voormalige koloniën, maar ook collaborateurs en latere generaties - die zich niet of onvoldoende herkennen in het collectieve geschiedbeeld, die hun huidige gemarginaliseerde positie verweven achten met de rol die zij in de dominante historische verbeelding toegeschreven krijgen. ${ }^{15}$

Het streven naar erkenning van deze groepen, het proces van politics of recognition, richtte zich veelal niet zozeer op de agenda van de beroepshistorici maar juist op de nationale overheid in de hoop daarmee de samenleving als geheel te bereiken. ${ }^{16}$ Bestudering van dit proces in de politieke arena laat zien dat het bevechten van maatschappelijke ruimte voor de vertolking van historische ervaringen die in zekere zin afwijken van het dominante beeld van de Tweede Wereldoorlog veelal een kwestie van lange adem is. Het aanbieden van excuses en het maken van financiële gebaren, zoals ook het oprichten van monumenten, musea en herinneringscentra, soms aangevuld met historische studies, zijn vaak het resultaat van decennialange ontwikkelingen en inspannin- 
gen. Deze institutionalisering en erkenning vormen bovendien geen definitief sluitstuk van herinneringen die nu officieel gesanctioneerd zijn. Ze maken, met terugkerende herdenkingsdagen, tijdelijke tentoonstellingen en door het aanspreken van nieuwe publieksgroepen, onderdeel uit van een langetermijnontwikkeling.

Met de officiële sanctionering is het geschiedbeeld niet automatisch bij iedereen aangepast. Oude, gevestigde beelden kunnen lang doorwerken, hoewel het niet vaststaat dat dit fenomeen zich in de populaire cultuur per definitie sterker voordoet dan elders. Daar hebben we nog betrekkelijk weinig zicht op. Want waar de academische historiografie naar behoren in kaart is gebracht, en waar voor een groeiend aantal landen tevens de ontwikkelingen geanalyseerd worden rond oorlogsmonumenten en -musea, ${ }^{17}$ herdenkingen en herinneringsgemeenschappen, en in mindere mate ten aanzien van het geschiedenisonderwijs, $^{18}$ weten we nog relatief weinig over de verbeelding van de oorlog in romans, speelfilms, stripverhalen, games en in andere presentaties.

Wat doorgaans versnipperd in kaart is gebracht op enkele deelterreinen wordt gekenmerkt door een sterke verkaveling en door een weinig representatieve selectie. ${ }^{19}$ Diverse studies gaan in op de verbeelding van de Tweede Wereldoorlog in bepaalde culturele producten, vaak met een accent op deelonderwerpen als jodenvervolging, daderschap of verzet. De ene studie richt zicht op de representatie in enkele romans, een volgende op films, en weer een andere op toneelstukken of beeldverhalen, ${ }^{20}$ veelal uit één bepaald land. Daarbij blijkt een sterke voorkeur te bestaan voor het inzoomen op vooraanstaande makers, zoals Claude Lanzmann of Harry Mulisch, en op de meest toonaangevende en vernieuwende werken uit hun oeuvre die de oorlog verbeelden. De aandacht voor hun werk is waardevol maar vloeit met name voort uit intellectuele, creatieve, literaire en verwante artistieke beoordelingscriteria. Daarentegen acht ik het zinvol om de historische beeldvorming in zowel canonieke als niet-canonieke creaties ook los van deze sterk esthetische merites te bestuderen en daarin nadrukkelijk ook de aard en omvang van het bereik mee te nemen. Een zeker onderscheid daarbij tussen 'hoge' en 'lage' cultuur kan verhelderend werken voor een goed begrip van de strekking, verwachtingen en effecten van bepaalde culturele producties. Maar in een samenleving waarin het bereik van dergelijke cultuurvormen door elkaar loopt kan dit geen doorslaggevend selectiecriterium zijn in de bestudering van de populaire historische cultuur. ${ }^{21}$

Dat onderzoekers de aandacht bijvoorbeeld richten op een vroege graphic novel zoals Art Spiegelmans Maus is lovenswaardig, maar de duiding als literair meesterwerk zingt het los van het medium van stripverhalen waarmee het evenzeer verbonden is. ${ }^{22}$ Positionering als een soort op zichzelf staand outsider icoon - te visueel voor de letterkunde, te literair voor het beeldverhaal - draagt 
niet bij aan ons begrip van deze vertolking en van de bredere culturele context. Een ruimere blik, met aandacht voor ook minder hoog aangeslagen vertolkingen - ontspanningslectuur zonder pretenties, B-films en tv-series die vooral verstrooiing bieden - is daarentegen behulpzamer. Zo zijn populaire sitcoms zoals het Britse 'Allo 'Allo en Dad's Army (Daar komen de schutters), die langdurig en grootschalig bekeken werden in Europa, ongeacht hun humoristische insteek de moeite van het bestuderen waard vanuit de vraag hoe deze vertolkingen de historische beeldvorming van de kijkers bevestigen, vernieuwen of relativeren.

Willen we bovendien beter zicht krijgen op het brede spectrum waaraan historische participanten zich laven dan dienen de afzonderlijke media en de uiteenlopende genres niet gescheiden maar juist in samenhang bestudeerd te worden. Incidentele studies naar meer en minder canonieke uitingen zijn slechts een eerste stap op weg naar een meer geïntegreerde benadering van oorlogsverbeeldingen. Een open vizier is noodzakelijk om daadwerkelijk te kunnen zien wat de bouwstenen zijn waarmee deelnemers in de populaire historische cultuur hun beelden van de oorlog hebben opgebouwd.

De basis voor de beeldvorming over de Tweede Wereldoorlog is door de opkomst van nieuwe media en vertolkingsmogelijkheden verder verbreed. Met de opmars van het computergebruik in huishoudens vanaf de jaren tachtig van de twintigste eeuw kwam de oorlog vanaf een nieuw scherm de privésfeer binnen. Tot de populaire genres van de video games of computerspellen behoort een groeiend aantal strategische spellen en zogeheten first-person shooters waarin handelingen van soldaten aan diverse oorlogsfronten worden uitgebeeld. Als inspiratiebronnen fungeren onder meer enkele bekende historische onderwerpen, naast eigentijdse conflicten. Dat daarbij frequenter wordt teruggegrepen op de Tweede Wereldoorlog dan op de Eerste Wereldoorlog of de Koude Oor$\log$, bevestigt de aanhoudende fascinatie. ${ }^{23}$

Dergelijke verbeeldingen illustreren niet alleen de wijze waarop nieuwe media de basis voor de historische cultuur verbreden. Ze onderstrepen bovendien opnieuw de aanwezigheid van een spelelement in diverse vertolkingen. ${ }^{24}$ Bordspelen kenden reeds kort na de bevrijding verschillende varianten die voortborduurden op recente oorlogservaringen, zoals de distributiebeperkingen en het onderduiken, en de laatste jaren maken bordspelen zoals Axis \& Allies of Roads to Moscow een nieuwe opmars waarmee zeker niet uitsluitend een publiek van kinderen wordt bediend.

Kenmerkend voor veel spelachtige presentaties, de vertrouwde plastic soldaatjes en modelbouwvliegtuigen inbegrepen, is het idee van de speler zelf actief handelend te kunnen optreden in de verbeelde bezigheden. Vanaf een veilige afstand in tijd en vaak ook ruimte is hij niet alleen in staat zich onder te 
dompelen in de beoogde situatie uit het verleden die nadrukkelijk als onvoltooid en te veranderen wordt voorgesteld - iets waaraan de door voortdurend verfijndere grafische detailering steeds realistischer ogende spelmogelijkheden onmiskenbaar bijdragen. De keuzes en handelingen van de speler versterken bovendien de suggestie deze geschiedenis te kunnen (mee)sturen.

Het is bepaald niet de enige wijze waarop participanten in de historische cultuur zich actief opstellen. Die actieve opstelling kent meer digitale voorbeelden, zoals het bouwen van websites over oorlogsthema's, het maken van YouTube-filmpjes over historische lieux de mémoire zoals de Atlantikwall ${ }^{25}$ of het bijdragen aan Wikipedia-lemma's over personen en gebeurtenissen uit de Tweede Wereldoorlog. ${ }^{26}$ Naast dit doorgaans zeer toegankelijke digitale universum biedt ook de analoge wereld tal van mogelijkheden. In de sfeer van vrijetijdsbesteding bezoekt menig toerist in binnen- en buitenland sporen en presentaties van de oorlog (waaronder vele verzorgd door geïnstitutionaliseerde aanbieders) of andere verwijzingen daarnaar, van schuilkelder tot oorlogsbodem en van doorgangskamp tot militaire begraafplaats. De mate waarin toeristen in deze uiteenlopende settings menen het verleden te 'ervaren' ${ }^{27}$ - dergelijke experience is een belangrijke maatstaf in de hedendaagse leisure economy - en de wijze waarop dit hun omgang met en betekenisverlening aan de Tweede Wereldoorlog beïnvloedt vraagt nader onderzoek. Maar het grote areaal aan benutte mogelijkheden wijst erop dat zij actief keuzes maken uit het aanbod.

Het verdient uiteraard aanbeveling om gradaties te onderscheiden in de fequentie van oorlogsgerelateerde interesse en de mate van betrokkenheid. Die zijn naar verwachting bovengemiddeld bij personen voor wie de Tweede Wereldoorlog een hobby vormt. Dit betreft alleen al in Nederland naar schatting enkele duizenden gemotiveerde amateur-geschiedbeoefenaars, -conservatoren en -acteurs. Zij verzamelen historische objecten, leggen lokaal en internationaal contact met burgers, veteranen en andere ooggetuigen of spelen bij wijze van re-enactment veldslagen na. In hun actieve opstelling produceren én consumeren zij oorlogsvertolkingen. Hun fascinatie voor de oorlogsgeschiedenis is steeds sterk, de mate waarin zij een publiek bereiken is wisselend.

Juist de imposante variatie aan populaire vertolkingen van de oorlog, die op meer en minder actieve wijze aanschouwd, beoefend en toegeëigend kunnen worden, maakt het begrijpelijk dat de bestudering daarvan vooralsnog fragmentarisch is. Verdieping van ons inzicht in de veranderende maatschappelijke betekenis van de Tweede Wereldoorlog, en van ons begrip van de hedendaagse werking van de populaire historische cultuur in het algemeen, vereist een meer omvattende analyse. 
Zo een analyse vraagt meer oog voor het gegeven dat oorlogsvertolkingen niet alleen een rol spelen in de nationale context waarin ze tot stand komen. Zo kennen re-enactmentbijeenkomsten niet zelden een internationaal deelnemersveld, vindt historisch toerisme in belangrijke mate plaats in den vreemde terwijl ook het publiek van veel historische websites niet beperkt blijft tot het eigen land. Deze transnationale verspreiding vormt een wezenlijke maar onderbelichte karakteristiek van de eigentijdse historische cultuur.

Populaire romans worden geregeld vertaald, speelfilms kennen dikwijls een verspreiding tot ver buiten het land van herkomst en computergames zijn vaak al van meet af aan gericht op een internationaal publiek. Aansprekende vertolkingen van aspecten van de Tweede Wereldoorlog vormen doorgaans geen uitzondering op de mogelijkheid van internationale distributie buiten de eigen lands-, taal- of cultuurgrenzen. Zodoende bestaat er wereldwijd een levendige import en export van oorlogsverbeeldingen, van historische ervaringen.

Veel vertolkingen van de Tweede Wereldoorlog zijn ingekaderd in het perspectief van één bepaald land, omdat zowel de historische cultuur als dominante culturele productiepatronen vaak op die wijze zijn ingericht. Die specifieke situering verhindert echter geenszins dat dergelijke presentaties ook toegankelijk kunnen zijn voor nieuwe publieken elders. Bekend is bovenal het Amsterdamse voorbeeld van Anne Franks Het Achterhuis. Dat de internationale faam van haar boek vooral wereldwijd gestimuleerd werd nadat de Amerikaanse editie was verwerkt tot een Broadway-theaterstuk en een daaropvolgende Hollywood-verfilming zegt ook iets over het belang van economische en politieke zwaartepunten en aspecten in het culturele veld waarmee rekening moet worden gehouden. ${ }^{28}$ Bovendien wijst dit op het toenemende belang van remediation en transmedialiteit ${ }^{29}$ van oorlogsverbeeldingen, waarbij zowel vertolking als toe-eigening van oorlogsgeschiedenissen via meerdere kanalen plaatsvindt.

Daniel Levy en Natan Sznaider wezen al in 2002 op de wijze waarop mediaverbeeldingen van de Holocaust in een globaliserende wereld - onder meer verspreid via televisie - vanaf de jaren zestig in toenemende mate onderdeel gingen vormen van lokale leefwerelden. Deze wijze van toe-eigening duiden zij aan als cosmopolitan memory die naast de nationale herinnering staat. Juist doordat de dramatische thematiek van de nationaalsocialistische jodenvervolging zich liet abstraheren tot een morele kwestie van goed en kwaad, kon het de landsgrenzen overstijgen. Dit resulteerde in een gemeenschappelijke historische fascinatie in landen waar de Holocaust zich had voltrokken (Duitsland), waar deze werd verbeeld (Verenigde Staten) en waar deze als legitimatie van staatsvorming (Israël) werd gehanteerd. Als sociologen beschouwen Levy en Sznaider dit fenomeen, waarin ze nadrukkelijk het zelfkritische vermogen van 
de maatschappelijke omgang met deze pijnlijke geschiedenis betrekken, als blijk van grotere onderlinge verbondenheid en als middel om een gedeeld bewustzijn te versterken, zelfs als een model voor een gemeenschappelijke Europese herinnering. ${ }^{30}$ Een dergelijk prescriptief model stuit op scepsis onder historici, maar niettemin krijgen vooraanstaande cultuurwetenschappers, zoals Aleida Assmann, terecht meer oog voor het feit dat uiteenlopende verschijningsvormen van memory vanzelfsprekend noch uitsluitend gekaderd zijn in de natiestaat. $^{31}$

Wie alleen al een blik werpt op de internationale verspreiding van oorlogsromans, egodocumenten en films - van zeer uiteenlopende status - vindt veel materiaal om die aanname te staven en te nuanceren. Naast het werk van Anne Frank exporteerde Nederland nog tientallen werken gebaseerd op 'onze' oorlogservaringen, waaronder romans van Harry Mulisch en W.F. Hermans ${ }^{32}$ evenals verfilmingen daarvan (De Aanslag, Als twee druppels water). Tegenover die export van romans en egodocumenten, van speelfilms en documentaires staat een veel omvangrijkere import. Daartoe behoren niet alleen Belgische oorlogsvertolkingen uit het gezamenlijke taalgebied, van Louis-Paul Boon tot Hugo Claus, maar bovenal een ruim aantal vertalingen. Reeds kort na de bevrijding verschenen al vertalingen van Britse, Duitse, Amerikaanse, Russische en Zweedse romans en jeugdboeken. Een voorlopige inventarisatie leert dat van de tussen 1946 en 1968 in Nederland uitgebrachte fictietitels die betrekking hadden op de Tweede Wereldoorlog ruim driekwart van buitenlandse origine was. In deze literatuurproductie waren de Britten, na het Nederlandse aandeel, het sterkst vertegenwoordigd met ongeveer tweehonderd titels. Het geallieerd perspectief, waaraan de Amerikanen een honderdtal en de Russen ongeveer vijftien titels toevoegden, was daarmee dominant maar monolithisch noch monopolistisch. Want ook voorheen vijandelijke landen kregen ruimte. Zo droegen Oost- en West-Duitsland om en nabij de 150 titels bij in deze eerste naoorlogse periode, die aangevuld kunnen worden met een klein aantal vertalingen uit het Italiaans en Japans. Ongeveer negentig titels kwamen uit andere voormalige bezette landen in Europa. ${ }^{33}$ Neutraal gebleven staten als Zweden en Zwitserland waren met circa vijftien titels vertegenwoordigd.

Deze kwantitatieve quick scan geeft aan dat de import aan oorlogsvertolkingen niet uitsluitend werd bepaald door een gedeelde bezettingservaring of een gedeelde positie in het geallieerde kamp. Evenzeer woog de veranderende culturele oriëntatie mee, waarin de blik verschoof van Duitsland en Frankrijk naar het Angelsaksische cultuurgebied. Kwalitatief onderzoek naar het aanbod en de receptie moet meer duidelijkheid bieden over de inhoud van deze vertolkingen (de thema's, de protagonisten, de geografische lokaliseringen) en over wijze van toe-eigening. Dat betreft met name de mate waarin het verbeelde oorlogs- 
verleden beschouwd werd als dat van 'de ander', in hoeverre het als vergelijkbaar of overeenkomstig gold met wat als eigen geschiedenis werd beschouwd, en over de criteria die daarbij gehanteerd worden. Van belang daarbij is ook om vast te stellen of en in welke mate de oorlogsvertolkingen van elders, om met James Wertsch te spreken, zogeheten narrative templates bevatten: vereenvoudigde schematische weergaven van dramatische historische episoden waarmee naties en andere groepen zich kunnen identificeren om betekenis te geven aan dat verleden. ${ }^{34}$ De herkenbaarheid van deze templates, die niet zelden teruggrijpen op oudere historische ervaringen van vóór de Tweede Wereldoorlog, en mogelijke overeenkomsten tussen verschillende landen kunnen de kaders verduidelijken van de impliciete of expliciete gemeenschappen waarmee mensen zich in historische zin verbonden voelen en identificeren. ${ }^{35}$

Om scherper zicht te krijgen op de karakteristieken van de populaire verbeeldingen van de Tweede Wereldoorlog is het niet alleen nodig om de in het onderzoek gangbare kaders inzake geografische en culturele herkomst losser te hanteren. Ook een andere categorisering dient hier tegen het licht gehouden te worden, namelijk de genre-indeling tussen feit en fictie. Uiteraard is het loslaten daarvan geen vanzelfsprekendheid voor een historicus, gehecht als deze is aan zijn professionele streven om feiten en ontwikkelingen te reconstrueren en deze naar beste vermogen te scheiden van ongefundeerde weergaven, mythevorming en persoonlijke opvattingen. Maar de bestudering van de populaire historische cultuur is, anders dan de studie van het historisch proces zelf, er niet primair op gericht om de juistheid vast te stellen van populaire geschiedbeelden. Centraal staat veeleer de vraag welke geschiedbeelden er circuleren en wat de impact daarvan is, wie vanuit bepaalde kennis, opvattingen en emoties er welke betekenissen aan hecht. Vanzelfsprekend is het van belang vast te stellen in hoeverre deze verbeeldingen gebaseerd zijn op de historische feiten, met name om te zien hoe deze verbeeldingen zich verhouden tot de wetenschappelijke historiografie en andere geïnstitutionaliseerde vormen van geschiedbeoefening en de daar gangbare vormen van contextualisering en interpretatie. Maar het meewegen van de feitelijke juistheid of onjuistheid dient plaats te vinden vanuit een besef dat de maatstaven van de historicus wat dat betreft niet steeds gedeeld worden door brede publieksgroepen. Historici moeten de publieksmaatstaven niet als richtsnoer nemen, maar wie een zo goed mogelijk begrip wil krijgen van karakter, invulling en betekenis van de populaire historische cultuur dient zich voldoende rekenschap te geven van de eigen opvattingen van de participanten in die cultuur.

Er bestaat onmiskenbaar weerstand tegen het gebruik van fictie in historische vertolkingen, niet in de laatste plaats waar het gaat om verbeeldingen van de Tweede Wereldoorlog. Critici hanteren in die context begrippen als tri- 
vialisering en banalisering om aan te geven dat dergelijke vertolkingen, opgevat als sentimentele kitsch, huns inziens geen recht doen aan het verleden. ${ }^{36}$ Die bezwaren gelden in het bijzonder voor populaire representaties van de Holocaust. Elie Wiesel verwoordde zijn - mede vanuit de joodse traditie ingegeven weerzin om de jodenvervolging publiekelijk audiovisueel te willen verbeelden en in commerciële zin te exploiteren krachtig in de beroemde zin 'stop insulting the dead'. ${ }^{37}$

Waar het de Holocaust betreft hangt deze overtuiging nauw samen met de opvatting dat dit historisch fenomeen uniek is en met de stellige overtuiging dat de Holocaust niet te bevatten is. Om nogmaals met Wiesel te spreken: Auschwitz is, en blijft, een universum buiten het universum. Maar ook als we er van uitgaan dat de dramatische geschiedenis van de Holocaust slechts beperkt kan worden overzien en verbeeld, ${ }^{38}$ dat we ons onvoldoende kunnen verplaatsen in de ervaringen en het leed van de betrokkenen en dat we niet volledig recht kunnen doen aan de geschiedenis van alle slachtoffers, dan nog bestaat hiervoor een sterke belangstelling. Er is een onmiskenbare behoefte dit gebeuren op enigerlei wijze te aanschouwen en er kennis van te nemen. Wetenschappelijke geschiedschrijving, documentaires en egodocumenten, door Wiesel aangereikt als alternatieven, voldoen niet aan ieders behoefte en belangstelling. Indien het volgens bepaalde morele of ethische standaarden niet voldoet, beantwoorden populaire, deels gefictionaliseerde verbeeldingen niettemin aan een zekere vraag. ${ }^{39}$ Dat geldt niet alleen voor de Holocaust, het geldt evenzeer voor de representatie van de Tweede Wereldoorlog in het algemeen.

Ook als we de risico's van vertekening, manipulatie en selectiviteit voor ogen houden moet erkend worden dat verbeelding die tevens fictieve elementen inzet een oud en machtig wapen is waarmee door het schetsen van tijdsbeelden en karakteriseringen het inzicht in historische situaties, en derhalve ook in de oorlogsgeschiedenis, kan worden vergroot. Die overtuiging staat tegenover de vrees voor trivialisering maar kent minder uitgesproken verdedigers. Het gebruik van fictie kan fungeren als aanvulling op een feitelijke geschiedweergave en wordt daar ook niet per definitie strijdig mee geacht. Een voorbeeld daarvan treffen we al kort na de bevrijding aan bij de verzetsorganisaties LO (Landelijke Organisatie voor hulp aan onderduikers) en LKP (Landelijke Knokploegen). Als voorloper van het in 1951 te verschijnen gedenkboek Het Grote Gebod publiceerden de voormalige illegale werkers in 1946 een bundeling novellen van onder meer Anne de Vries en K. Norel, mede als reactie op de reeds verschenen verzetsliteratuur die 'niet altijd betrouwbaar' werd geacht. Zo wilde men het tekort bestrijden 'aan inzicht in mentaliteit en practische uitvoering van het verzet'. De daartoe gepresenteerde novellen, geenszins alle 'tot in feiten histo- 
risch verantwoord', beoogden niet zozeer een historische weergave maar moesten niettemin 'een indruk' geven van het illegale werk en zo 'de juiste sfeer van het verzetswerk' presenteren. ${ }^{40}$ Twee herdrukken lijken te onderstrepen dat de lezers geen bezwaar maakten.

Oorlogsvertolkingen met fictieve elementen bestaan in talloze soorten en maten, van vroege verzetsnovellen tot recente educatieve stripverhalen van de Anne Frank Stichting en het Indisch Herinneringscentrum Bronbeek. ${ }^{41}$ De aandrang om een waardeoordeel te vellen over uiteenlopende oorlogsvertolkingen is soms moeilijk te weerstaan. Maar de eerste vraag die relevant is vanuit het perspectief van de populaire historische cultuur heeft niet primair betrekking op wenselijkheid of feitelijke juistheid, maar is die naar de betekenissen van dergelijke vertolkingen voor de daarmee bereikte publieksgroepen. Het zonder onderscheid vermengen van feit en fictie mag onwenselijk zijn, het automatisch gelijk stellen van fictie aan trivialisering is evenmin raadzaam. Om nader zicht te kunnen krijgen op de relevantie van het onderscheid tussen feit en fictie, verdient het aanbeveling te onderzoeken of, wanneer en in welke mate participanten in de historische cultuur een dergelijk onderscheid maken en ter zake achten.

De zorg omtrent trivialisering berust niet uitsluitend op het feit dat de weergave van het verleden niet correct is. Een belangrijke bijkomende reden voor deze zorg, niet in de laatste plaats onder historici, is dat geschiedenis onvoldoende serieus wordt genomen, dat de hedendaagse band met het verleden als te zwak geldt. Deze observatie komt deels voort uit onwennigheid. De band met het verleden staat immers steeds in verbinding met het collectieve kader van waaruit wordt teruggeblikt. Nu het lange tijd vanzelfsprekend geachte belang van het nationale verleden onder druk is komen te staan biedt de soms weinig overzichtelijke variatie aan klein- en grootschalige kaders van waaruit historische episoden zoals de Tweede Wereldoorlog worden vertolkt en toegeeigend weinig houvast. Behalve divers is de omgang met de Tweede Wereldoorlog bovendien soms ook lichtvoetig waaruit valt op te maken hoe de oorlog inmiddels gehistoriseerd wordt en op afstand komt te staan - een temporele distantiëring die eveneens een zeker houvast wegneemt.

Terwijl de vanzelfsprekende afbakening en invulling van historische cultuur aan diepgaande en wijdverbreide verandering onderhevig is, een verandering die blijk geeft van vrijheid en variatie, is er wat de Tweede Wereldoorlog betreft tegelijkertijd sprake van een krachtig moreel gefundeerd maatschappelijk appèl om niet te vergeten. Dat appèl wordt zowel nationaal als internationaal geformuleerd en kent in de westerse wereld omschrijvingen als devoir de mémoire en obligation to remember. Die begrippen richten zich behalve op de Tweede én Eerste Wereldoorlog ook op andere dramatische episoden uit de 
geschiedenis: genocides, slavernij en kolonialisme. Het blijven herinneren van de slachtoffers hiervan acht de filosoof Avishai Margalit een ethische verplichting. Margalit beschouwt dit echter niet als een wereldwijde vanzelfsprekendheid aangezien hij hierbij bovenal vertrouwt op herinneringsgemeenschappen met sterke onderlinge relaties. Die traceert hij behalve op familieniveau ook op nationaal niveau. ${ }^{42}$ Maar dit impliceert dat een veelomvattende internationale of zelfs mondiale gemeenschap te zwakke onderlinge relaties heeft om daadwerkelijk een universele plicht tot herinneren te ervaren en om zulke sterke conclusies te verbinden aan het verleden. ${ }^{43}$

In de populaire historische cultuur, die als veelkoppig transnationaal fenomeen gestalte krijgt, zijn de onderlinge relaties tussen de participanten vaak allesbehalve sterk. Het betreft uiteenlopende belangstellenden in wisselende verbanden met diverse beweegredenen. Een zelf opgelegde plicht tot herinneren vormt niet de alles overkoepelende drijfveer van de populaire oorlogsvertolkingen en -toe-eigeningen. De historische interesse die gestalte krijgt in deze cultuur is niet alleen gericht op contemplatief herdenken en ook niet uitsluitend op slachtofferschap. Maar grote diversiteit betekent niet per definitie dat deze manieren van omgang met het verleden geen gemeenschappelijke betekenissen kunnen vervullen, geen kenmerken als empathie kunnen bevatten of geen invloed kunnen hebben op gemeenschappen die sterkere onderlinge relaties koesteren. Is het niet veeleer zo dat we nog te weinig vertrouwd zijn met de populaire historische cultuur om daar al te stellige verwachtingen aan te kunnen koppelen?

Historici betrachten in beginsel distantie, zowel ten aanzien van hun historische onderwerp als ten aanzien van hun publiek. ${ }^{44}$ Wanneer overheden, instanties en groeperingen anderen verplichten kennis te nemen van een bepaald verleden, vertonen historici veelal een gezonde dosis scepsis. Ook bezorgdheid over het publiek is hen niet vreemd. Dat kan zich enerzijds uiten in een zekere aarzeling wanneer het publiek zich al te sterk identificeert met een verleden of zelfs meent dit verleden daadwerkelijk nog te kunnen 'beleven'. Anderzijds worden historici teleurgesteld wanneer het publiek het verleden onvoldoende serieus neemt. In beide gevallen wordt immers de complexiteit en schakering van het verleden, evenals de relatie met het heden, tekort gedaan.

Maar deze beide omgangsvormen met het verleden laten zien dat 'het publiek' als eenduidige massa niet bestaat. Daar komt bij, zo heb ik betoogd, dat presentatiewijzen van geschiedvertolkingen veranderen, dat de keuzevrijheid van participanten in de historische cultuur is toegenomen, dat voorts de kaders waarin geschiedenis wordt toegeëigend aan verandering onderhevig zijn en dat genres diffuser worden. Dit heeft geleid tot een dynamische situatie in de populaire historische cultuur, die zeker waar het vertolkingen van de zo sterk in de 
belangstelling staande Tweede Wereldoorlog betreft pregnant naar voren komt.

Uitingen van populaire historische cultuur zijn niet per definitie beter, democratischer of evenwichtiger dan de geïnstitutionaliseerde varianten van de historische cultuur. Ze bereiken niet steeds het grootst mogelijke publiek, ze vertonen vormen van selectiviteit en staan bloot aan commerciële wetmatigheden. Maar ze gelden vaak als toegankelijk en bieden in hun variëteit iets dat diverse groepen aanspreekt. Het bestaan van deze populaire oorlogsvertolkingen is een onmiskenbaar cultureel gegeven dat de aandacht van historici en andere cultuurwetenschappers verdient. Om een scherper beeld te kunnen krijgen van de hedendaagse betekenis van de Tweede Wereldoorlog dienen de vertolkingen en ontwikkelingen in de populaire historische cultuur ongeacht hun vorm en herkomst met open vizier tegemoet te worden getreden. Daarbij moet de rol van de participanten in de historische cultuur serieus worden genomen. Een zorgvuldige bestudering van de veranderende historische cultuur in brede zin helpt historici en anderen om te zien hoe hedendaagse burgers het verleden toe-eigenen door betekenissen te hechten aan uiteenlopende oorlogsvertolkingen. Het leert ons uiteindelijk meer over wie op dit strijdtoneel op een gegeven moment de regisseurs, acteurs en toeschouwers zijn en tot waar hun invloed reikt. Vanuit een onbevooroordeelde reflectie op dit krachtenspel kunnen historische professionals vervolgens nader invulling geven aan hun wezenlijke maatschappelijke rol.

Ik wil besluiten met een dankwoord.

Het aanvaarden van deze bijzondere leerstoel ervaar ik vanuit nederigheid als een eervol moment vanwege het in mij gestelde vertrouwen. Ik dank het college van bestuur van de Erasmus Universiteit voor het mogelijk maken van deze leerstoel en ik ben het NIOD Instituut voor Oorlogs-, Holocaust- en Genocidestudies evenals de Koninklijke Nederlandse Akademie van Wetenschappen zeer erkentelijk voor hun vitale bijdrage bij het instellen ervan. Ook aan de Erasmus School of History, Culture and Communication, in de persoon van decaan professor Dick Douwes, betuig ik graag mijn dankbaarheid om ruimte te willen bieden aan dit initiatief. Hein Klemann en Siep Stuurman mogen hier evenmin onvermeld blijven.

Dit moment voert mijn gedachten terug naar mijn voorzichtige eerste schreden op het wetenschappelijke pad. De keuze voor het vak geschiedenis was in 1985 ietwat toevallig maar bleek uiteindelijk de weg te openen voor de bestudering van een rijkdom aan historische én actuele fenomenen. Eenieder die mij daarbij de weg heeft gewezen, me beter heeft leren kijken en lezen, zoeken en 
vinden, denken en uitdrukken ben ik zeer erkentelijk. Dat geldt allereerst voor de historici en communicatiewetenschappers aan de Radboud Universiteit Nijmegen en voor Guy Mans in het bijzonder. Ook koester ik degenen die mij vervolgens als freelancende historicus durfden bloot te stellen aan de praktische publieksgeschiedenis en daarbij optraden als waardevolle adviseurs. Evenzeer ben ik de cultuurhistorici aan de Universiteit Utrecht erkentelijk bij wie ik het voorrecht had mijn proefschrift te mogen schrijven. Ed Jonker dank ik hartelijk voor de wijze waarop hij eruditie en menselijkheid combineert en deelt en voor de hartelijke betrokkenheid en steun die hij al vele jaren biedt, ook wanneer mijn interesses enige bevreemding oproepen. Ook promotor Wijnand Mijnhardt verdient uiteraard mijn dank terwijl ik bovendien met genoegen terugdenk aan de collegiale sfeer bij de promovendi van OGC en Huizinga Instituut en bij de contractonderzoekers rond Joost Dankers.

Na mijn promotie had ik het genoegen om bij Paul Klep en zijn collega's deel te mogen nemen aan het 21ste-eeuwse reilen en zeilen van de Nijmeegse historici alvorens ik als onderzoeker aantrad bij de Faculteit der Historische en Kunstwetenschappen, hier in Rotterdam. Dit vormde een hernieuwde kennismaking met Maria Grever, immer scherp, gedreven en energiek. Ik ben haar buitengewoon erkentelijk voor de inspirerende samenwerking die nu opnieuw gestalte krijgt en waar ik met veel genoegen naar uitkijk.

In 2006 maakte ik de overstap naar het NIOD. Ik trof in het instituut een stimulerende intellectuele uitvalsbasis maar evenzeer een warme en hechte gemeenschap die veel voor mij betekent. Peter Romijn en Marjan Schwegman gaven me alle ruimte voor verdere ontplooiing en daar ben ik ze zeer dankbaar voor. Het enige wat ik nu betreur is dat ik teveel dierbare collega's van het NIOD heb, huidige en voormalige, om hier met naam te kunnen bedanken. Vanuit het domein Publieksgeschiedenis zet ik de intellectuele uitwisseling en coöperatie graag voort. En dat geldt eveneens voor mijn collega's van de interuniversitaire onderzoeksgroep Dynamiek van de Herinnering.

$\mathrm{Nu}$ ik terugkeer bij het Center for Historical Culture verheug ik me op de samenwerking met mijn enthousiaste collega's. Ook vertrouw ik erop de hartelijke contacten met de andere historici, cultuur- en mediawetenschappers aan de faculteit op vruchtbare wijze uit te kunnen bouwen. En niet in de laatste plaats hoop ik $u$, studenten en promovendi, met wederzijdse begeestering te mogen stimuleren om ons vakgebied nader te ontginnen.

Ik realiseer mij dat ik vele namen ten onrechte onvermeld laat, waaronder die van mijn onmisbare mede-auteurs, maar ook van bevlogen archivarissen en bibliothecarissen, doortastende uitgevers, betrokken financiers en van meer dan dienstvaardige ondersteunende collega's. Zij allen verdienen mijn grote dank. In een heel andere vertakking van het historisch bedrijf trof ik een inspi- 
ratiebron die evenmin onvermeld mag blijven, de redactie van het Tijdschrift voor Geschiedenis, een even aangenaam als eerbiedwaardig gezelschap.

Jacco Pekelder dank ik graag hartelijk voor alle gezamenlijke bespiegelingen. Oscar Westers verdient mijn erkentelijkheid voor zijn nimmer aflatende streven het historisch bedrijf te relativeren.

Bovenal wil ik mijn dank uitspreken aan mijn ouders die mede aan de basis stonden van mijn historische en andere fascinaties en deze steeds ruimhartig stimuleerden. Mijn grootste dank geldt Andrea Ramírez Ramírez. Zonder haar liefde en steun, haar toewijding en daadkracht zou ik hier niet staan. Met Pablo en Maru vormt zij in alle opzichten mijn thuis - dat is vele malen waardevoller dan ik hier zou kunnen uitdrukken.

Zeer gewaardeerde toehoorders, ik dank u voor uw aandacht. 


\section{Curriculum Vitae}

Kees Ribbens (1967) studeerde Nieuwste Geschiedenis aan de Radboud Universiteit in Nijmegen. Na zijn doctoraalexamen in 1991 werkte hij enige tijd als freelance historicus. Als assistent in opleiding bij de afdeling Cultuur-, Mentaliteits- en Ideeëngeschiedenis van de Universiteit Utrecht schreef hij vervolgens Een eigentijds verleden. Alledaagse historische cultuur in Nederland, 1945-2000 waarop hij in 2001 promoveerde. Hij was als onderzoeker en docent verbonden aan de Universiteit Utrecht, de Radboud Universiteit Nijmegen en de Erasmus Universiteit Rotterdam. Daarnaast was hij redactiesecretaris van het Tijdschrift voor Geschiedenis. Sinds 2006 is Ribbens verbonden aan het NIOD Instituut voor Oorlogs-, Holocaust- en Genocidestudies te Amsterdam waar hij actief is als senior onderzoeker op het terrein van de publieksgeschiedenis. Vanaf 1 januari 2013 bekleedt hij de bijzondere leerstoel Populaire Historische Cultuur en Oorlog aan de Erasmus School of History, Culture and Communication van de Erasmus Universiteit Rotterdam. Vanuit het Center for Historical Culture aldaar is zijn belangstelling onder meer gericht op de wijzigende maatschappelijke betekenissen van het oorlogsverleden. 


\section{Noten}

1. Ik dank Ed Jonker, Jacco Pekelder en Oscar Westers evenals Martine van den Heuvel voor hun kritische en constructieve commentaar op eerdere versies van deze tekst.

2. Uiteenlopende analyses zijn te vinden in Jerome De Groot, Consuming history. Historians and heritage in contemporary popular culture (Londen 2009); Barbara Korte, Sylvia Paletschek ed., History goes Pop. Zur Repräsentation von Geschichte in populären Medien und Genres (Bielefeld 2009) en Kees Ribbens, Een eigentijds verleden. Alledaagse historische cultuur in Nederland, 1945-2000 (Hilversum 2002). Klassieke en breed opgezette introducties zijn David Lowenthal, The past is a foreign country (Cambridge 1985) en Raphael Samuel, Theatres of memory. Volume 1: past and present in contemporary culture (London, New York 1994).

3. Andrew Granath, 'A Brighter Past', The Times Educational Supplement 14 juni 2002. De uitspraak is afkomstig van een BBC-medewerker naar aanleiding van een internationaal congres voor historische tv-producenten.

4. Zie voor een vergelijking tussen geschiedenis en 'herinnering': Ed Jonker, Ordentelijke geschiedenis : herinnering, ethiek en geschiedwetenschap (Utrecht 2008).

5. Maria Grever en Kees Ribbens, Nationale identiteit en meervoudig verleden. WRR Verkenningen 17 (Amsterdam 2007) 75-84.

6. http://entoen.nu/tweedewereldoorlog en http://entoen.nu/annefrank

7. David Barnouw, Geschiedenis van Nederland 1940-1945. De Canon van de Duitse bezetting (Zutphen 2010).

8. Ook elders staan canonieke geschiedbeelden onder druk, vgl. Maria Grever en Siep Stuurman ed., Beyond the Canon. History for the Twenty-First Century (Basingstoke 2007).

9. In een interview met Martin Sommer uit SP-politicus Jan Marijnissen zijn zorgen over het beoogde museum, mede omdat de gekozen thematische ordening 'nogal postmodern' oogt: Martin Sommer, 'De tijdbalk is weg, "nu wordt het een hutspot"', de Volkskrant 9 mei 2009. Daarop ontkent NHM-directeur Erik Schilp dat het museum een 'postmoderne hutspot' wordt. Harmen Bockma, '"Onze geschiedenis is zo veel breder". Nationaal Historisch Museum moet vooral ook een plek worden waar jongeren zich thuis voelen', de Volkskrant 11 mei 2009.

10. Willem Frijhoff, Dynamisch erfgoed (Amsterdam 2007), vgl. ook Roy Rosenzweig en David Thelen, The presence of the past. Popular uses of history in American life (New York 1998).

11. Dit wordt bovendien versterkt door de toegenomen mogelijkheden van cultuurhistorisch toerisme dat zich steeds meer is gaan richten op een gevarieerd palet aan onderwerpen uit vooral de nieuwste geschiedenis.

12. Een eerste aanzet daartoe inzake de media vormde de Rotterdamse oratie van Jan Bank, Oorlogsverleden in Nederland (Baarn 1983).

13. Frank van Vree, In de schaduw van Auschwitz. Herinneringen, beelden, geschiedenis (Groningen 1995); Frank van Vree en Rob van der Laarse ed., De dynamiek van de herinnering. Nederland en de Tweede Wereldoorlog in een internationale context 
(Amsterdam 2009); Madelon de Keizer en Marije Plomp ed., Een open zenuw. Hoe wij ons de Tweede Wereldoorlog herinneren (Amsterdam 2010); Rob van Ginkel, Rondom de stilte. Herdenkingscultuur in Nederland (Amsterdam 2011); Rob van der Laarse, Nooit meer Auschwitz? Erfgoed van de oorlog na Europa's eeuw van de kampen (Amsterdam 2012).

14. Voor een kritische beschouwing zie onder meer Wulf Kansteiner, 'Finding meaning in memory. A methodological critique of collective memory studies', History and Theory 41 (2002) 179-197 en Susan Hogervorst, Herinneringsculturen van Ravensbrück in Europa, 1945-2010 (Hilversum 2010) 13-29, 222-236.

15. Esther Captain, Achter het kawat was Nederland. Indische oorlogservaringen en -herinneringen 1942-1995 (Kampen 2002); Kees Ribbens, Martijn Eickhoff, Joep Schenk, Oorlog op vijf continenten. Nieuwe Nederlanders \& de geschiedenissen van de Tweede Wereldoorlog (Amsterdam 2008) 287-315.

16. Zie voor een - omstreden - overzicht Chris van der Heijden, Dat nooit meer. De nasleep van de Tweede Wereldoorlog in Nederland (Amsterdam, Antwerpen 2011). $\mathrm{Vgl}$. het desbetreffende discussiedossier onder redactie van James Kennedy en Peter Romijn in BMGN - Low Countries Historical Review 128.2 (2013) 71-108.

17. Kees Ribbens en Esther Captain, Tonen van de oorlog. Toekomst voor het museale erfgoed van de Tweede Wereldoorlog (Amsterdam 2011); Ola Svein Stugu, 'Exhibiting the war. Approaches to World War II in museums and exhibitions', in Helle Bjerg, Claudia Lenz, Erik Thorstensen ed., Historicizing the uses of the past. Scandinavian perspectives on history culture, historical consciousness and didactics of history related to World War II (Bielefeld 2011), 189-206.

18. Dienke Hondius, Oorlogslessen. Onderwijs over de oorlog sinds 1945 (Amsterdam 2010).

19. Niettemin kunnen de volgende studies als inspirerend gelden: Daniel H. Magilow, Elizabeth Bridges en Kristin T. Vander Lugt ed., Nazisploitation! The Nazi image in low-brow cinema and culture (New York, Londen 2012); Sara Buttsworth, Maartje Abbenhuis ed., Monsters in the Mirror. Representations of Nazism in Post-War Popular Culture (Santa Barbara 2010); Michael Keren en Holger H. Herwig ed., War memory and popular culture. Essays on modes of remembrance and commemoration (Jefferson NC 2009); Ronald M. Smelser en Edward J. Davies II, The Myth of the Eastern Front: The Nazi-Soviet War in American Popular Culture (Cambridge 2008); M. Paul Holsinger en Mary Anne Schofield ed., Visions of war. World War II in popular literature and culture (Bowling Green $\mathrm{OH}, 1992)$; Michael Paris, Warrior nation. Images of war in British popular culture, 1850-2000 (Londen 2000).

20. Een mooi voorbeeld is: Isabelle Doré-Rivé, Guy Krivopissko ed., Traits résistants. La résistance dans la bande dessinée de 1944 à nos jours (Lyon 2011).

21. In navolging van Maltby beschouw ik populaire cultuur op pragmatische wijze als 'a form of dialogue society has with itself', een dynamisch fenomeen dat refereert aan veelal wijdverbreide culturele uitingen en vertolkingen (zonder a priori uitsluiting van enig genre). Dit kan variëren van idealistische grass-roots initiatieven tot onmiskenbaar commerciële producten. Vgl. Richard Maltby, Dreams for Sale: Popular culture in the twentieth century (London 1989) 14. 
22. Deborah R. Geis ed., Approaches to Art Spiegelman's "Survivor's Tale" of the Holocaust (Tuscaloosa 2003). Vgl. ook de eigen reflectie van de auteur in Art Spiegelman, MetaMaus: A look inside a modern classic, Maus (New York 2011).

23. Eva Kingsepp, 'Immersive Historicity in World War II Digital Games' HUMAN IT 8.2 (2006) 60-89; Gunnar Sandkühler, 'Der Zweite Weltkrieg im Computerspiel: Ego Shooter als Geschichtsdarstellung zwischen Remediation und Immersion'. In: Erik Meyer ed., Erinnerungskultur 2.0. Kommemorative Kommunikation in digitalen Medien (Frankfurt am Main 2009) 55-65.

24. In game studies leidt dit tot vruchtbare bezinning op Johan Huizinga, Homo ludens. Proeve eener bepaling van het spel-element der cultuur (Haarlem 1950). Een digitale versie is beschikbaar op http://www.dbnl.org/tekst/huiz003homo01_01/

25. Relevant op YouTube is voorts onder meer de populariteit van geparodieerde fragmenten uit de Duitse Hitler-film Der Untergang van Oliver Hirschbiegel (2004) zie: Christopher J. Gilbert, 'Playing With Hitler: Downfall and Its Ludic Uptake', Critical Studies in Media Communication, published online February 2013, http:// www.tandfonline.com/doi/full/10.1080/15295036.2012.755052

26. Maren Lorenz, 'Wikipedia als "Wissensspeicher« der Menschheit - genial, gefährlich oder banal?', in: Meyer ed., Erinnerungskultur 2.0., 207-236.

27. Vgl. Rob van der Laarse, De oorlog als beleving. Over de musealisering en enscenering van Holocaust-erfgoed (Amsterdam 2011).

28. Zie bijv. Barbara Kirshenblatt-Gimblett en Jeffrey Shandler ed., Anne Frank Unbound. Media, imagination, memory (Bloomington, Indianapolis 2012).

29. Ann Rigney, 'When the monograph is no longer the medium: historical narrative in the online age', History and Theory 49 (2010) 100-117 biedt inzicht in de wijze van aanpassen in digitale vertolkingsvormen.

30. Daniel Levy en Natan Sznaider, Erinnerung im globalen Zeitalter: Der Holocaust (Frankfurt am Main 2001); idem, 'Memory Unbound. The Holocaust and the Formation of Cosmopolitan Memory', European Journal of Social Theory 5.1 (2002) 87106.

31. Aleida Assmann en Sebastian Conrad, 'Introduction', in: idem ed., Memory in a Global Age: Discourses, Practices and Trajectories (Basingstoke 2010). Vgl. ook Susan Rubin Suleiman, Crises of memory and the Second World War (Cambridge MA, 2006). Michael Rothberg heeft de aandacht voor de transnationale herinnering verder verdiept door deze te verbinden met de multiculturele herinnering. Opvallend is dat ook hij daarvoor de Holocaust-herinnering aangrijpt, en bestudeert hoe deze zich verhoudt tot de traumatische herinneringen rond de naoorlogse dekolonisatie. Michael Rothberg, Multidirectional Memory: Remembering the Holocaust in the Age of Decolonization (Stanford 2009).

32. Aanbevelenswaardig is de deels autobiografisch geïnspireerde studie van Ewoud Kieft, Oorlogsmythen. Willem Frederik Hermans en de Tweede Wereldoorlog (Amsterdam 2012).

33. Van deze circa negentig titels was ongeveer de helft Frans. Stageverslag Anneleen Arnout, De herinnering aan de Tweede Wereldoorlog in de populaire literatuur in internationaal perspectief. Analyse van verzamelde oorlogsromans: productie en receptie (Amsterdam, Utrecht 2009).

34. James V. Wertsch, Voices of Collective Remembering (Cambridge 2002) 61-62 
35. Vgl. Grever en Ribbens, Nationale identiteit en meervoudig verleden, 137-153.

36. Opmerkelijk in dat verband was ook de karakterisering het werk van de Duitse documentairemaker Guido Knopp door de Amerikaanse historicus Wulf Kansteiner als 'unterhaltsame Geschichtspornographie'. Wulf Kansteiner, 'Die Radikalisierung des deutschen Gedächtnisses im Zeitalter seiner kommerziellen Reproduktion. Hitler und das "Dritte Reich" in den Fernsehdokumentationen von Guido Knopp', Zeitschrift für Geschichtswissenschaft 51 (2003), 626-648, aldaar 648.

37. Elie Wiesel, 'Art and the Holocaust: Trivializing Memory', The New York Times 11 juni 1989.

38. Het is hier niet de plaats om in extenso in te gaan op discussies over de uniciteit en verbeeldbaarheid van de Holocaust. Zie o.a. Saul Friedlander ed., Probing the Limits of Representation. Nazism and the "Final Solution" (Cambridge 1992) en Gavriel D. Rosenfeld, 'The Politics of Uniqueness: Reflections on the Recent Polemical Turn in Holocaust and Genocide Scholarship', Holocaust and Genocide Studies 13.1 (1999) 28-61.

39. Als enkel voorbeeld mag hier een empirische korte-termijn studie gelden van de Afdeling Kijk- en Luisteronderzoek NOS, Rondom Holocaust. Een onderzoek naar de invloed van een omstreden tv-serie op jongeren (Hilversum 1980). In de literatuur wordt nauwelijks naar deze studie verwezen.

40. Gedenkboekcommissie, 'Ten geleide', in: K. Norel, Anne de Vries, Frits de Zwerver e.a., Den vijand wederstaan. Historische schetsen van de Landelijke Organisatie voor hulp aan onderduikers, Landelijke Knokploegen en Centrale Inlichtingendienst (Wageningen 1946) 8-11.

41. Eric Heuvel, Ruud van der Rol, Menno Metselaar, De ontdekking (Amsterdam 2003); Eric Heuvel, Ruud van der Rol, Lies Schippers, De Zoektocht (Amsterdam 2007); Eric Heuvel, Ruud van der Rol, De terugkeer (Amsterdam 2010).

42. Avishai Margalit, The Ethics of Memory (Cambridge 2004).

43. Deze verwachting roept overigens de vraag op hoe dit zich verhoudt tot bijvoorbeeld het initiatief van de Verenigde Naties uit 2005 om op 27 januari een wereldwijde jaarlijkse dag ter herdenking van de Holocaust in te stellen.

44. Een waardevolle bespiegeling over de relatie van historici met het publiek is Remieg Aerts, 'De lege kathedraal: over geschiedwetenschap, vaderlandse geschiedenis en het publiek', in: Herman Paul, Henk te Velde ed., Het vaderlandse verleden. Robert Fruin en de Nederlandse geschiedenis (Amsterdam 2010) 195-220, 273-278. 